\title{
editorial
}

\section{What future for studying the past?}

The editors of Archaeological Dialogues are proud to open this issue of the journal with the three winning submissions to the first Archaeological Dialogues Essay Competition. Among the twenty-two manuscripts, coming from fourteen different countries, an independent and international jury of leading archaeologists has indicated the essays by Nick Shepherd (University of Cape Town), Reuben Grima (Institute of Archaeology, London) and Nicola Laneri (Istituto Universitario Orientale in Naples) as their top three. The best way to congratulate these laureates is to express our sincere hope that their work may contribute to shaping the future of the discipline. To that end, readers are, as always, invited to comment upon their articles.

The idea for organising an essay competition on 'the future of archaeology' came, paradoxically enough, from history. The last large and international essay competition organised in our field dated already from 1971 when Antiquity editor Glyn Daniel spurred his readership to reflect upon the question 'Whither archaeology?'. The two winning essays by Glynn Isaac and Evžen Neustupný have become classics in their own right, but much time has passed since. In 2002, twenty years after Hodder's seminal essay 'Theoretical archaeology: a reactionary view' (1982) and forty years after Binford's landmark paper 'Archaeology as anthropology' (1962), Archaeological Dialogues asked a young generation of archaeologists to assess the current state of the discipline and the desired role of theoretical archaeology therein. Under the banner of 'What future for studying the past?', the old Enlightenment idea of the concours was thus revivified to address vital questions about archaeology at the start of the third millennium.

That the initiative was well received became not only clear through a host of enthusiastic e-mails after it was launched, but in particular through the number and geographic diversity of the participants. With submissions coming from institutions in England, the USA, Canada, Germany, Australia, South Africa, Scotland, the Netherlands, Belgium, Italy, Greece, Poland, Estonia and Russia (there are even more nationalities if one looks at individuals rather than institutions), the international dimension was fully guaranteed. Most essays were written by individual authors, although two were co-authored pieces. Eight papers were written by women, against fourteen by men. All participants were born between 1963 and 1980, with the sixties and seventies being equally represented.

On this last point: Archaeological Dialogues had opted to apply an age restriction for potential participants, in that candidates had to be born after 1962, the year of Binford's infamous article. Some colleagues were not entirely happy with this. One person accused us of 'blatant ageism' and said that it was 'illegal in the USA and in Australia'. Another one promised to forward this 'discrimination case' to his lawyer who would 'carry it to Strasbourg, if necessary'. And he concluded: 'see you in court, baby!'. 
It seems as if some clarification is required here. Of course, as organisers we do not contest the fact that one can be young in scholarship without being young in years, nor do we underestimate the fact that in a field like archaeology some people enter the subject later in life than others. We are convinced that these mature students, coming from the outside, can often bring to the discipline refreshing experiences and ideas gathered elsewhere. The age limit to the essay competition was never established to exclude mature students, who in fact belong to the group of students and 'new', rather than 'young' scholars which we try to reach with the journal. In the everyday world of academia, it is usually these new scholars (who typically are finishing or have just finished their Ph.D.) who find it difficult to express their views. One of the aims of Archaeological Dialogues has accordingly always been to promote this group by actively encouraging them to submit articles and by providing more practical assistance than usual during the production process. The essay competition is another means to lend a voice to this group of 'young scholars'. The age restriction was just a means to prevent established leading academics to dominate the debate. Because of the formal nature of the essay competition, however, we have had to draw a strict line which inevitably and unintentionally will have excluded some people other than 'established academics'. We felt that it was nevertheless impossible to make exceptions to the age limit, especially as the competition was already underway.

Something, however, struck us in this critique of ageism. With only one exception, all these criticisms came from scholars working in the Anglo-American world. Now it may very well be the case that an awareness of this form of discrimination is higher in these parts of the world than elsewhere (and it may be fuelled by the relatively large proportion of mature students there). But if that is the case, this sensitivity for one form of discrimination reveals at least an enormous blind spot for another form of discrimination, the dimensions of which may be far more monumental than the alleged ageism. Though there is no term for it, it could be called linguism - i.e. the tendency to reproduce and maintain hegemonic power relations on the basis of differential foreign language capacities (read: fluency in English). Comparable to racism, sexism, speciesism, and, yes, ageism, 'linguism' consists of an intricate set of, often unconscious, mechanisms whereby a large number of individuals are granted lesser opportunities on the basis of an irrelevant, though heavily discriminatory criterion, in this case the relative proficiency in one specific language.

Nobody, not even candidate participants from the non-English speaking world, complained about the fact that the essay competition was in English. Of course not, Archaeological Dialogues is an English-language journal and as such it does comply with the fact that English has become the dominant tongue in international academic debate. While we do not necessarily deplore this - for the first time since the Renaissance there is again a genuine lingua fran$c a$ for scholarly discussion - we do regret the fact that, as a living language, it has created an incredible imbalance between native speakers and those who use English as a second or third language in terms of symbolic capital (international prestige, access to resources, readership size, etc). This imbalance led a continental archaeologist to remark wryly that Archaeological Dialogues' next essay competition should be in Hungarian, Lithuanian or Linear B.

Of course, one blind spot does not pardon another one. But the extreme sensitivity to one form of discrimination in this particular part of the world that is already unduly bene- 
fiting from another form of discrimination is somewhat upsetting, to say the least. The moral indignation expressed by some Anglo-American colleagues is therefore, at best, selective. It refuses to acknowledge power relations in the academic field that go beyond the well-known parameters of age, race, class, and gender to include the central notion of language.

This is why Archaeological Dialogues strongly encourages submissions from outside the Anglo-American world. As a journal originally rooted in Continental archaeology it has always attempted to create a truly international forum for discussion and it has, as may be expected, been paying a price for this (translation costs, of course, but also the efforts of extending and maintaining very diverse networks in a variety of languages). This is also why the members of the jury were explicitly asked to ignore differences in English proficiency between the competition participants. 'Well-written' meant 'clarity of thought', not 'fluency in English'.

We had the pleasure to work with the following members of the jury: Sue Alcock (University of Michigan), Sarah Tarlow (University of Leicester), Richard Bradley (University of Reading), Peter van Dommelen (University of Glasgow), and Kristian Kristiansen (Göteborg University). David Van Reybrouck (University of Leuven) served as the non-voting president. Each of the members of the jury commented on the overall quality of the essays submitted, they prepared and motivated their individual top ten and agreed to have these rankings pooled into a final classification. Here is the full jury report:

The pool of twenty-two essays, submitted from a satisfyingly wide range of countries, also satisfyingly demonstrates that our field is being - yet again and as it must be - reassessed and criticized in a healthy fashion. As one might expect from such an open competition, the quality of submission varied; some authors were fuelled perhaps more by passion than by mature reflection, but all were passionate and committed to a future of studying the past.

Two themes recurred throughout many of the essays. First, there was a concern to bridge seemingly unproductive divides between theoretical positions, or between 'theory' and 'practice'. Though the key elements of post-processual thinking seem well absorbed, there is also an avoidance of dogma and a retreat from the polemics and paradigm shifts that dominated the writings of the 1970s, the 1980s and parts of the last decade. The younger generation does not appear to seek further revolution, but rather to balance and refine its legacy: they seem dissatisfied, but not really anarchic or radical.

The other, even more strongly marked leitmotif was a concern for public engagement with archaeology. This took, in some cases, a negative form: worries over funding structures, self-criticism for remoteness and aridity in our research and in public presentation. The perceived dichotomy was in these cases simply asserted to be a bad thing, rather than setting out evidence and arguing a case (one could, for example, make a reasonable case that there should be a split between public and academic archaeology, and that sophisticated interpretations need to explore complex and difficult ideas which might not be suitable for public consumption). In other instances, the essays celebrated (if never naively) a belief that archaeology can and must be made 
to matter to many and different public audiences. This growing concern to create a more holistic archaeology that is socially responsible and politically aware emerges as one self-defined, highly compelling mission of this archaeological generation.

Having read, compared and ranked the participating essays, we have come up with the following laureates of the Archaeological Dialogues Essay Competition:

Nicola Laneri's essay 'Crossing boundaries' was felt to be genuinely novel and exciting. Focusing on the communication (or non-communication) between archaeologists and the 'external world', Laneri uses some well-chosen examples (e.g. the BASE Institute 'discovery' of Mount Sinai) to energize the essay and its concerns about our ongoing dissociation from the broad cultural arena. The author draws in a wide range of concepts (performance, Action Research), people (Fo, Barthes), and suggestions (more innovative and accepting use of artistic and graphic media, especially in 'popular' forms). His is a fairly sophisticated and passionate piece, although what it implies in terms of interpretative strategies is left open. He becomes third.

On the second place comes Reuben Grima's 'Archaeology as encounter'. Twining together two central themes in archaeology, i.e. the emerging interest in our ability to track subjective experience in the past, and the growing concern for making archaeology 'meaningful and accessible' to a wider public, Grima clearly outlines the shared roots of these developments, while also quietly dissecting our tendency to 'create narratives' and 'disseminate narratives' in two entirely different fashions. This is a very careful and well balanced essay that clearly identifies how and where the discipline fails to play a role of significance in modern society: it goes right to the heart of the problem, making it very clear that this is an issue that concerns the entire developed Western world and not just 'extreme cases'.

But the first place - and the 1000 euro award kindly provided by the Free University of Amsterdam - goes to Nick Shepherd for his essay 'Heading south, looking north'. His stylish, very well written essay is an intelligently troubled piece which comes to its own conclusions about what has been achieved and where we have failed, and which taps away at central issues regarding the social value of archaeology. Starting from the deep roots in South African archaeology and the experience of archaeology in a divided community, it translates these experiences very well to the academic realm by providing clear guidelines for reshaping the discipline. It thus powerfully combines personal experience with intelligent vision. 